\title{
STRUKTUR SASTRA LISAN LA DHANGU SARINA DAN BUNGAEJA DI PULAU BUTON SULAWESI TENGGARA
}

\author{
Nadir La Djamudi
}

Wakil Dekan I

FKIP Universitas Muhammadiyah Buton

Jalan Wa Ode Waum No.15 A, Tanganapada,

Murhum, Baubau, Sulawesi Tenggara

pos-el: nadirladjamudi@gmail.com

\begin{abstract}
La Dhangu Sarina story theme is about La Dhangu Sarina whose size posture more than ordinary buman being. Then, the mandate of the story are; first, parents should be able to steer or guide the potencyof their child. Second, man proposes but God disposes. This story used the progressive, straight, forward plot. The main character is La Dhangu Sarina, then additional characters are his father, King Wolio, the representative of the Dutch Company. Characterizations which is used in this story is analytical characterization. While, the background story are: time, place, and atmosphere.

Theme of the story of Bungaeja is Bungaeja and Jibirilu love story. The mandate of theory are: first, love requires effort, sacrifice, fortitude, either for man or woman. Second; do not be jealous on other people happiness of others because it would be harmful for yourself. This story uses a progressive straight forward plot. The main character of the story, then, are Bungaeja and Jibirilu. Additional characters are Kambampu, her beautiful girl friends, Sapati (mother of Bungaeja), Kinapulu (parents of Kambampu), Si Hasani. Characterizations of this story is analytical characterization. While the background (setting) in this story are: time, place, and atmosphere.
\end{abstract}

Keywords: structure, oral literature of Buton island

\begin{abstract}
Abstrak
Tema cerita La Dhangu Sarina adalah La Dhangu Sarina dengan ukuran postur tubuh lebih dari manusia biasa. Amanatnya, yakni pertama, orang tua hendaknya dapat mengarahkan atau membimbing potensi anaknya; kedua, manusia hanya dapat merencanakan, tetapi Tuhanlah yang menentukan segalanya. Cerita ini menggunakan plot maju, lurus, progresif. Tokoh utama adalah La Dhangu Sarina. Tokoh tambahan adalah ayah La Dhangu Sarina, Raja Wolio, utusan Kompeni. Penokohan atau perwatakan yang digunakan adalah penokohan analitik. Sedangkan latar cerita adalah: waktu, tempat, dan atmosfir.
\end{abstract}


Tema cerita Bungaeja, yakni kisah cinta Jibirilu dengan Bungaeja. Amanatnya, yakni pertama cinta membutuhkan usaha keras, pengorbanan, ketabahan, baik itu bagi laki-laki maupun bagi perempuan; kedua; janganlah iri pada kebahagiaan orang lain karena itu akan berakibat buruk bagi diri sendiri. Cerita ini menggunakan alur lurus, alur maju, atau alur progresif. Tokoh utama adalah Bungaeja dan Jibirilu. Tokoh tambahan adalah Kambampu, gadis-gadis cantik teman Kambampu, Sapati (Ibu dari Bungaeja), Kinapulu (orang tua Kambampu), Si Hasani. Penokohan atau perwatakan dalam cerita Bungaeja adalah penokohan secara analitik. Sedangkan latar (setting) yang digunakan dalam cerita ini, yakni waktu, tempat, dan atmosfir.

Kata kunci: struktur, sastra lisan pulau Buton

\section{PENDAHULUAN}

Kebinekaan suku bangsa dalam bingkai Negara Kesatuan Republik Indonesia berimbas kepada kebinekaan budaya yang di dalamnya terdapat keraganan bahasa daerah yang dimilikinya. Kekhasan bahasa daerah masing-masing etnis itu senantiasa mengundang perhatian berbagai pemerhati khusunya peneliti bahasa dan sastra daerah.

Sastra daerah yang menggunakan bahasa daerah adalah salah satu isu penting yang sangat urgen diungkapkan melalui kajian ilmiah. Karena pentingnya hal ini maka dewasa ini, sedang maraknya kajian interdisipliner sastra dengan bidang ilmu lain, seperti kajian sastra daerah dari sudut pandang sosial-budaya, agama, nilai, lingkungan, dan lain-lain.

Kajian sastra khususnya sastra daerah (sastra lisan) tidak hanya berorientasi pada pendokumentasian dan pelestarian sastra lisan dan bahasa daerah yang digunakannya, akan tetapi lebih pada pengungkapan serta aktualisasi nilai-nilai yang terkandung di dalamnya. Berbagai upaya ilmiah tersebut banyak memberikan manfaat terhadap eksistensi sastra daerah bagi kehidupan pembaca dan pemiliknya.

Dijelaskan dalam GBHN 1999-2004 butir 2.f tentang kebudayaan, kesenian, dan pariwisata (1999:106) bahwa ada upaya untuk melestarikan apresiasi nilai kesenian dan kebudayaan tradisional serta menggalakkan dan memberdayakan sentral-sentral kesenian untuk merangsang berkembangnya kesenian nasional yang lebih kreatif dan inovatif sehingga menumbuhkan rasa kebanggaan nasional.

Beberapa penelitian sastra lisan di Pulau Buton yang menggunakan Bahasa Wolio sebagai langkah awal mereka memusatkan kajian pada masalah inventarisasi karya sastra lisan, seperti apa yang dilakukan oleh Mattalitti, dkk. (1985) dan La Djamudi (1993). Ada juga penelitian yang memusatkan kajian pada analisis struktur karya sastra lisan tersebut, seperti apa yang dilakukan oleh Sande, dkk. (1998), sedangkan Suhartini (2000) dalam bentuk kajian wacana. Selain itu La Djamudi (2005) memusatkan kajiannya pada nilai-nilai yang terdapat pada cerita rakyat.

Bertolak pada uraian di atas maka fokus penelitian ini adalah bagaimanakah struktur intrinsik sastra lisan La Dhangu Sarina dan Bungaeja. 
Secara morfologi dijelaskan oleh Badudu (1984:18) bahwa kata kesusastraan berasal dari kata dasar susastra yang diberi imbuhan ke-an. Kata dasar susastra sebenarnya kata dasar kedua (secundairestam) karena dapat diuraikan pula atas $s u$ dan sastra; keduaduanya berasal dari bahasa Sansekerta; su berarti baik, sastra berarti tulisan. Kata susastra sendiri dalam bahasa Indonesia tak hidup pemakaiannya, kecuali dalam kata bentukan kesusastraan. Untuk pengertian susastra dewasa ini dipakai sastra saja, sedangkan kesusastraan mengandung pengertian jamak, yaitu semua yang meliputi sastra. Kesusastraan Indonesia artinya semua hal yang meliputi sastra Indonesia.

Effendy (dalam Badudu, 1984:5) menjelaskan bahwa "Kesusastraan (sastra) ialah ciptaan manusia dalam bentuk bahasa lisan maupun tulisan yang dapat menimbulkan rasa bagus." Sedangkan Pradopo (1997:10) mengemukakan pengertian sastra sebagai kesimpulan pendapat baik dari Gazali, B.A., B. Simorangkir, Zuber Usman, Suparlan D.S., maupun H.F. Sitompul yang mengakui bahwa kesusastraan itu karya seni yang ditulis dengan bahasa yang indah. Secara singkat dikemukakan pula oleh Wellek dan Warren (1993:3) bahwa "Sastra adalah suatu kegiatan kreatif, sebuah karya seni."

Menurut Mattalitti, dkk. (1985:1) dijelaskan bahwa sastra lisan adalah bagian dari suatu kebudayaan yang tumbuh dan berkembang di tengah-tengah masyarakat dan diwariskan secara terus-menerus secara lisan sebagai milik bersama. Shipley (dalam Gaffar, dkk., 1991:2) menjelaskan secara rinci bahwa sastra lisan adalah jenis atau kelas karya sastra tertentu, yang dituturkan dari mulut ke mulut, tersebar secara lisan, anonim, dan menggambarkan kehidupan masyarakat pada masa lampau. Jenis sastra lisan meliputi: (1) Bahasa rakyat: logat, sindiran, bahasa rahasia, dan mantra; (2) Ungkapan tradisional: peribahasa, pepatah, dan seloka; (3) Pertanyaan tradisional: teka-teki, wangsalan; (4) Puisi rakyat: pantun, syair, dan gurindam; (5) Cerita prosa rakyat: mite, legenda, dongeng, fabel, cerita jenaka; (6) Nyanyian rakyat.

\subsection{Aspek intrinsik karya sastra lisan prosa}

\section{1) Alur}

Secara spesifik, Nurgiantoro (2000:12) menjelaskan bahwa secara teoritis kita dapat membedakan plot ke dalam dua kategori, yaitu kronologis dan tak kronologis. Yang pertama disebut sebagai plot lurus, maju, atau dapat juga dinamakan progresif, sedang yang kedua adalah sorot-balik, mundur, flash-back, atau dapat juga disebut sebagai regresif. Sebuah plot dikatakan progresif jika peristiwa-peristiwa yang dikisahkan bersifat kronologis, peristiwa (-peristiwa) yang pertama diikuti oleh (atau: menyebabkan terjadinya) peristiwa-peritiwa yang kemudian.

\section{2) Tema dan amanat}

Menurut Esten (1990:16) tema adalah sesuatu yang menjadi persoalan di dalam sebuah karya sastra, apa yang menjadi persoalan utama dalam karya sastra. Tema sebagai persoalan merupakan sesuatu yang netral. Di dalam tema belum ada sikap, belum ada kecenderungan untuk memihak. Oleh karena itu, masalah apa saja dapat dijadikan tema di dalam sebuah karya sastra. Kita tidak mungkin menolak atau 
mengharamkan sebuah cipta sastra hanya karena temanya, sedangkan pemecahan suatu tema disebut amanat. Dalam amanat terlihat pandangan hidup dan cita-cita 
pengarang. Amanat dapat diungkapkan secara eksplisit (berterang-terangan) dan dapat juga secara implisit (tersirat).

3) Tokoh dan penokohan

Ada beberapa sudut pandang yang dapat digunakan membedakan jenis tokoh. Tokoh cerita (character) menurut Abrams (dalam Nurgiyantoro, 2000:165) adalah orang (orang) yang ditampilkan dalam suatu karya naratif, atau drama, yang oleh pembaca ditafsirkan memiliki kualitas moral dan kecenderungan tertentu seperti yang diekspresikan dalam ucapan dan apa yang dilakukan dalam tindakan, sedangkan penokohan sekaligus menyarankan pada teknik perwujudan dan pengembangan tokoh dalam sebuah cerita. Penokohan sekaligus mencakup masalah siapa tokoh cerita, bagaimana perwatakan, dan bagaimana penempatan dan pelukisannya dalam sebuah cerita sehingga sanggup memberikan gambaran yang jelas kepada pembaca.

4) Latar

Keckerbacker (dalam Gaffar, dkk., 1991:11) menjelaskan bahwa latar adalah tempat terjadinya peristiwa-peristiwa dalam suatu cerita, latar belakang fisik serta unsur tempat dan waktu dalam suatu cerita. Latar menunjukkan kepada pembaca kapan dan di mana peristiwa itu terjadi serta mempunyai hubungan dengan eksposisi. Eksposisi dalam uraian ini adalah pemaparan atau penghantar ke dalam situasi awal cerita yang akan disajikan.

\section{BAHAN DAN METODE PENELITIAN}

Penelitian menggunakan metode penelitian deskriptif kualitatif dan tergolong jenis penelitian kepustakaan (librery research). Data penelitian meliputi sejumlah kalimat yang menggambarkan atau menunjukkan struktur intrinsik dalam kedua teks sastra lisan. Sumber data penelitian adalah buku yang berjudul Sastra Lisan Wolio Mattalitti yang diterbitkan oleh Pusat Pembinaan dan Pengembangan Bahasa, Departemen Pendidikan dan Kebudayaan, Jakarta, 1985. Teknik pengumpulan data dilakukan dengan teknik baca dan teknik catat. Teknik analisis dengan pendekatan struktural.

\section{HASIL DAN PEMBAHASAN}

\subsection{Struktur Intrinsik Cerita Rakyat La Dhangu Sarina}

\subsubsection{Tema dan Amanat}

Adapun tema atau gagasan sentral dalam cerita La Dhangu Sarina adalah kelahiran La Dhangu Sarina yang memiliki ukuran postur tubuh lebih dari manusia biasa. Hal tersebut dapat dipahami melalui kutipan berikut.

1)"Pada pertengahan abad kesembilan belas hiduplah seorang yang bernama La Dhangu Sarina di sebuah pulau dalam pemerintahan Kerajaan Wolio. Perawakannya sangat mengherankan karena terlalu tinggi besar."

2)'Diceritakannya babwa La Dhangu Sarina waktu labirnya telah dapat menghabiskan satu tandan pisang kapok sekali makan. Jadi, telah dapat kita pikirkan bagaimana besar orangnya." 
Sedangkan pesan moral yang ingin disampaikan oleh pencerita yang biasa disebut amanat, yang dapat diperoleh melalui cerita ini adalah; pertama, orang tua hendaknya dapat mengarahkan atau membimbing potensi anaknya. Kedua, manusia hanya dapat merencanakan, akan tetapi Tuhan-lah yang menentukan segalanya. Hal ini dilakukan dengan menyimpulkan keseluruhan isi cerita atau dipahami secara implisit.

\subsubsection{Alur (plot)}

Berdasarkan deskripsi pada ringkasan cerita La Dhangu Sarina di atas, dapat dikemukakan bahwa cerita ini menggunakan plot maju, lurus, progresif. Peristiwaperistiwa dalan cerita ini dikisahkan secara kronologis, peristiwa (-peristiwa) yang pertama diikuti oleh (atau: menyebabkan terjadinya) peristiwa-peritiwa yang kemudian. Atau, secara runtut cerita dimulai dari tahap awal (penyituasian, pengenalan, pemunculan konflik), tengah (konflik meningkat, klimaks), dan akbir (penyelesaian). Jika dituliskan dalam bentuk skema, secara garis besar plot progresif tersebut akan berwujud sebagai berikut.

Bagian awal yaitu ketika lahir bayi yang bernama La Dhangu Sarina. Kejadiankejadian berikutnya, tahap tengah, yang merupakan inti cerita. Hal ini bermula ketika La Dhangu Sarina mulai dewasa, sampai sukses dalam pembinaan beladiri dan ketahanan fisik, dan akhirnya dipanggil menjadi pengawal kerajaan dengan segala kehebatannya. Tahap penyelesaian cerita yang bermula dengan tamu kerajaan dalam hal ini utusan Kompeni simpati dengan fisik La Dhangu Sarina dan menawarinya untuk dibawa keliling ke seluruh dunia. Penyelesaian dalam cerita ini berakhir ketika La Dhangu Sarina tidak jadi dibawa keliling karena telah meninggal dunia. Oleh karena menggunakan plot maju, progresif, sehingga kisahannya menunjukkan kesederhanaan juga tidak berbelit-belit, dan mudah diikuti.

\subsubsection{Tokoh dan Penokohan}

Tokoh utama (central character, main character) adalah tokoh yang diutamakan penceritaannya dalam cerita yang bersangkutan. Ia merupakan tokoh yang paling banyak diceritakan, baik sebagai pelaku kejadian maupun yang dikenai kejadian. Bahkan dalam cerita tertentu, tokoh utama senantiasa hadir dalam setiap kejadian dan dapat ditemui dalam tiap halaman buku cerita yang bersangkutan. Pada cerita lain, tokoh utama tidak muncul dalam setiap kejadian, atau tak langsung ditujukan dalam setiap bab, namun ternyata dalam kejadian atau bab tersebut tetap erat berkaitan, atau dapat dikaitkan, dengan tokoh utama. Dalam kegiatan sinopsis, tokoh utama adalah tokoh yang dibuat sinopsisnya. Tokoh yang memenuhi kriteria tokoh utama seperti yang diuraikan di atas adalah La Dhangu Sarina.

Tokoh tambahan (peripheral character) adalah tokoh yang frekuensi kemunculannya sangat sedikit dan itu pun mungkin dalam porsi penceritaan yang relatif pendek. Kemunculannya hanya ada jika ada keterkaitannya dengan tokoh utama secara langsung atau tak langsung. Tokoh tambahan tidak dimunculkan dalam kegiatan sinopsis. Tokoh yang memenuhi kriteria tokoh pembantu seperti yang diuraikan di atas adalah ayah La Dhangu Sarina, Raja Wolio, utusan Kompeni. 
Penokohan atau perwatakan yang digunakan dalam cerita La Dhangu Sarina adalah penokohan secara analitik, yaitu pengarang langsung menceritakan bagaimana watak tokoh-tokohnya. Hal ini dapat dicermati dalam deskripsi tokoh-tokoh dalam tabel berikut ini.

Tabel 1

Penokohan dalam cerita La Dhangu Sarina

\begin{tabular}{|c|c|c|c|c|}
\hline No. & Tokoh & Penokohan / Perwatakan & $\begin{array}{l}\text { Jenis / cara } \\
\text { Penokohan }\end{array}$ & Paragraf \\
\hline 1 & $\begin{array}{l}\text { La Dhangu } \\
\text { Sarina }\end{array}$ & $\begin{array}{l}\text { memiliki keluarbiasaan dibandingkan dengan } \\
\text { manusia biasa }\end{array}$ & analitik & 1,2 \\
\hline 2 & $\begin{array}{l}\text { Ayah } \\
\text { La Dhangu } \\
\text { Sarina }\end{array}$ & $\begin{array}{l}\text { orang tua yang cermat memahami, serta } \\
\text { mengarahkan atau membimbing potensi yang } \\
\text { dimiliki anaknya }\end{array}$ & analitik & 3 \\
\hline 3 & Raja Wolio & $\begin{array}{l}\text { pandai menjaga atau mempertahankan } \\
\text { kelanjutan kekuasaannya, antara lain } \\
\text { menjadikan La Dhangu Sarina sebagai } \\
\text { pengawal kerajaan. Juga mampu kerja sama } \\
\text { dengan negeri lain, yaitu Belanda dengan } \\
\text { menerima Kompeni sebagai utusannya }\end{array}$ & analitik & 5,7 \\
\hline 4 & $\begin{array}{l}\text { Utusan } \\
\text { kompeni }\end{array}$ & $\begin{array}{l}\text { orang yang diutus oleh Belanda untuk } \\
\text { melakukan persahabatan dengan Raja Wolio }\end{array}$ & analitik & 7 \\
\hline
\end{tabular}

\subsubsection{Latar (setting)}

Latar (setting) dalam sebuah cerita (narasi) merupakan latar belakang di mana para pelaku menjalani kehidupan mereka. Latar tempat memiliki pengaruh yang demikian kuat terhadap personalitas/pribadi, aksi/tindakan, dan cara berpikir para tokohnya. Ada tiga hal yang perlu dipertimbangkan dalam kaitannya dengan setting, yaitu: waktu, tempat, dan atmosfir. Apa latar dan jenis latar, serta kutipannya, secara jelas dapat dipahami melalui tabel berikut.

Tabel 2

Latar dalam cerita La Dhangu Sarina

\begin{tabular}{|c|c|c|c|}
\hline No. & Latar & Kalimat atau paragraf & Keteranga $\mathbf{n}$ \\
\hline 1 & Pertengan abad & 1) Pada pertengaban abad kesembilan belas hiduplah & \\
\hline & $\begin{array}{l}\text { ke sembilan } \\
\text { belas } 1\end{array}$ & $\begin{array}{l}\text { seorang yang bernama La Dhangu Sarina di sebuah } \\
\text { pulau dalam pemerintahan Kerajaan Wolio.... }\end{array}$ & Waktu \\
\hline 2 & $\begin{array}{l}\text { Pulau di } \\
\text { wilayah }\end{array}$ & $\begin{array}{l}\text { 1) Pada petrengahan abad kesembilan belas } \\
\text { hiduplah seorang yang bernama La Dhangu Sarina }\end{array}$ & Tempat \\
\hline & $\begin{array}{l}\text { kerajaan Wolio } \\
1\end{array}$ & di sebuah pulau dalam pemerintahan Kerajaan Wolio... & \\
\hline 3 & $\begin{array}{l}\text { Waktu } \\
\text { kelahiran La } \\
\text { Dharrgu Sarima }\end{array}$ & $\begin{array}{l}\text { 2)Diceritakannya bahwa La Dhangu Sarina waktu } \\
\text { labirnya telah dapat menghabiskan satu tandan } \\
\text { pisang kapok sekali mrakanl.... }\end{array}$ & Waktu \\
\hline 4 & $\begin{array}{l}2 \\
\text { Istana raja } 5\end{array}$ & 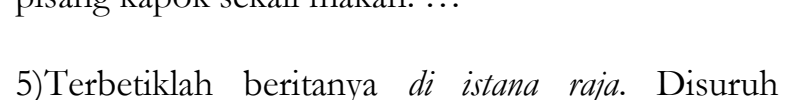 & \\
\hline
\end{tabular}

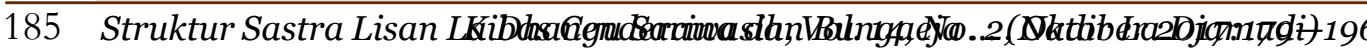


panggil Si La Dhangu Sarina agar datang ke istana.

Tinggallah La Dhangu Sarina di dalam istana. ..

$\begin{array}{lllll}5 \text { Sungai } 5 & 5) \ldots & \text { Telah menjadi pengawal raja bila } & \\ & \text { menyeberangi sungai biar bagaimana dalamnya, La } & \text { Tempat } \\ & \begin{array}{l}\text { Dhangu Sarina } \\ \text { tidak basah. }\end{array}\end{array}$

tidak basah. 


\subsection{Struktur Intrinsik Cerita Rakyat Bungaeja}

\subsubsection{Tema dan amanat}

Gagasan dominan sebagai sentral pengisahan yang biasanya disebut dengan tema, dalam cerita Bungaeja adalah kisah cinta Jibirilu dengan Bungaeja. Hal ini dapat ditunjukkan dengan memahami ringkasan cerita di atas atau memahami keseluruhan isi cerita. Cerita ini memang mengisahkan upaya keras Jibirilu menjejaki takwil mimpinya, hingga bertemu dengan Bungaeja dan akhirnya menikah, walaupun dengan berbagai tantangan.

Dari kisah pernikahan pasangan suami-istri Jibirilu dengan Bungaeja yang dihiasi berbagai tantangan sebagai pembentuk alur, serta penokohan cerita ini, dapatlah penulis menyimpulkan bahwa pesan moral secara implisit dan eksplisit yang disebut amanat, yang dapat dipetik dalam cerita ini adalah cinta membutubkan usaba keras, pengorbanan, ketabahan, baik itu bagi laki-laki maupun bagi perempuan. Hal tersebut antara lain terlihat pada kutipan berikut.

(21)"Mula-mula membujuk Bungaeja untuk bersikap acub tak acub terbadap Jibirilu. Menurut mereka sikap yang demikian itu merupakan alat uji bagi Jibirilu. Apakah bermental baik atau tidak. Andai kata sikapnya itu tidak diterima baik oleh Jibirilu berarti itu suatu tanda tidak setia kepadamu, bujuk para gadis itu kepada Bungaeja. Bujukan itu dilaksanakan oleh Bungaeja. Akan tetapi sikeap Bungaeja itu tetap diterima oleh Jibirilu dengan hati yang dingin. Menurut Jibirilu perlakuannya itu adalah wajar karena ia belum dewasa. Akbirnya, tipu daya mereka pada waktu itu tidak berbasil. Dengan demikian mereka kembali ke rumahnya masing-masing dengan hati yang kesal dan kecewa. Namun, mereka itu tidak putus asa, tetapi mencari kesengsaraan dan kehinaan."

(23)"Pada waktu kedua mempelai sementara duduk bersanding, datanglah rombongan Kambampu sebanyak empat pulub orang di tempat itu. Daya tipu mereka tidak lagi menggunakan akal, tetapi menggunakan tenaga dalam."

(24)"Sementara itu, tiba-tiba Kambampu bangkit dari tempat duduknya, lalu pergi ke belakang Jibirilu sambil menepuk bahunya. Dengan seketika cinta Jibirilu beralih kepada Kambampu. Acara pernikahan mereka segerah dibatalkan karena Jibirilu cinta lagi kepada Kambampu, babkan sebaliknya rasa benci dan muak kalau memandang wajah Bungaeja."

Amanat lain yang dapat diperoleh melalui kisahan cerita ini adalah janganlah iri pada kebahagiaan orang lain karena itu akan berakibat buruk bagi diri sendiri. Hal tersebut terpancar pada upaya jahat Kambampu kepada pasangan Jibirilu dan Bungaeja yang berakibat buruk bagi Kambampu. Kata pepatah, siapa yang gali lubang, dia sendiri yang akan jatuh ke dalamnya.

Akhirnya nasib Kambampu dapat kita baca pada kutipan berikut.

(29)"Sampai mereka di istana pernikahan antara Jibirilu dengan Bungaeja dilangsungkan kembali. Setelah beberapa bari perkawinan mereka berselang, Jibirilu bersama orang tuanya kembali ke negerinya, Kambampu rela mengikuti mereka walaupun ia dijadikan sebagai pembantu Bungaeja.” 


\subsubsection{Alur (plot)}

Cerita ini menggunakan cara kisahan kronologis yang biasa disebut alur lurus, alur maju, atau alur progresif. Peristiwa-peristiwa dikisahkan secara kronologis, yaitu peristiwa (peristiwa) yang pertama diikuti oleh (atau, menyebabkan terjadinya) peristiwa-peritiwa yang kemudian. Atau, secara runtut cerita dimulai dari tahap awal (penyituasian, pengenalan, pemunculan konflik), tengah (konflik meningkat, klimaks), dan akhir (penyelesaian). Jika dituliskan dalam bentuk skema, secara garis besar plot progresif kisahan cerita Bungaeja tersebut akan berwujud sebagai berikut.

Tahap awal cerita, berupa pengenalan. Bagian ini bermula ketika Jibirilu berangkat menuju ke suatu negeri menelusuri takwil mimpinya dengan menggunakan perahu bersama pengawalnnya. Kejadian-kejadian berikutnya, tahap tengah, yang merupakan inti cerita. Bagian ini bermula dengan konflik yang memuncak ketika Jibirilu tiba di negeri seberang dan memukul gong tujuh kali sehingga suaranya membahana ke seluruh negeri, sementara negeri itu masih berkabung atas meninggalnya salah seorang pejabat setempat. Akhirnya Jibirilu akan kawin dengan putri raja seberang yang bernama Bungaeja.

Klimaks terjadi ketika Jibirilu dan Bungaeja sedang bersanding di pelaminan, tibatiba Jibirilu dikena guna-guna dan meninggalkan pelaminan menuju rumahnya Kambampu. Tahap penyelesaian cerita, terjadi tawar-menawar antara keluarga Jibirilu dengan keluarga Kambampu dan terjadi kesepakatan. Pernikahan kembali dilanjutkan asal Kambampu tetap mengikut walaupun jadi pembantu majikan. Oleh karena kejadian-kejadian yang dikisahkan bersifat kronologis-yang secara istilah berarti sesuai dengan urutan waktu — sehingga alur penceritaannya sederhana dan tidak berbelit-belit, serta mudah diikuti.

\subsubsection{Tokoh dan Penokohan}

Tokoh utama (central character, main character) adalah tokoh yang diutamakan penceritaannya dalam cerita yang bersangkutan. Ia merupakan tokoh yang paling banyak diceritakan, baik sebagai pelaku kejadian maupun yang dikenai kejadian. Bahkan dalam cerita tertentu, tokoh utama senantiasa hadir dalam setiap kejadian dan dapat ditemui dalam tiap halaman buku cerita yang bersangkutan. Pada cerita lainnya, tokoh utama tidak muncul dalam setiap kejadian, atau tak langsung ditujukan dalam setiap bab, namun ternyata dalam kejadian atau bab tersebut tetap erat berkaitan, atau dapat dikaitkan, dengan tokoh utama. Dalam kegiatan sinopsis, tokoh utama adalah tokoh yang dibuat sinopsisnya. Tokoh yang memenuhi kriteria tersebut dalam cerita Bungaeja adalah Bungaeja dan Jibirilu.

Tokoh tambahan (peripheral character) adalat tokoh yang frekuensi kemunculannya sangat sedikit, dan itu pun mungkin dalam porsi penceritaan yang relatif pendek. Kemunculannya hanya ada jika ada keterkaitannya dengan tokoh utama secara langsung atau tak langsung. Tokoh tambahan tidak dimunculkan dalam kegiatan sinopsis. Tokoh yang memenuhi kriteria tokoh tambahan (peripheral character) adalah Kambampu, gadis-gadis cantik teman Kambampu, Sapati (Ibu dari Bungaeja), Kinapulu (orang tua Kambampu), Si Hasani. 
Penokohan atau perwatakan yang digunakan dalam cerita Bungaeja adalah penokohan secara analitik, yaitu pengarang langsung menceritakan bagaimana watak tokoh-tokohnya. Hal ini dapat dicermati dalam tabel deskripsi tokoh-tokoh berikut ini.

Tabel 3

Penokohan dalam cerita Bungaeja

\begin{tabular}{|c|c|c|c|c|}
\hline No. & Tokoh & Penokohan / Perwatakan & $\begin{array}{l}\text { Jenis / cara } \\
\text { Penokohan }\end{array}$ & Paragraf \\
\hline 1 & Bungaeja & $\begin{array}{l}\text { gadis cantik, ramah, } \\
\text { simpatik, putri seorang raja }\end{array}$ & Analitik & 1 \\
\hline 2 & Jibirilu & $\begin{array}{l}\text { pemuda gagah, sopan, kaya, } \\
\text { simpatik, disenangi oleh } \\
\text { semua lapisan masyarakat, } \\
\text { beradab. }\end{array}$ & Analitik & $\begin{array}{l}20,14 \\
16,32\end{array}$ \\
\hline 3 & Kambampu & $\begin{array}{l}\text { gadis cantik, pengacau, } \\
\text { pemimpin } \\
\text { gadis, pemilik ilmu hitam, } \\
\text { dan pengusik kebahagian } \\
\text { orang lain. }\end{array}$ & Analitik & $\begin{array}{l}18,19 \\
21,23\end{array}$ \\
\hline 4 & $\begin{array}{l}\text { Sapati (ibu dari } \\
\text { Bungaeja) }\end{array}$ & $\begin{array}{l}\text { tegas, bijaksana, dan } \\
\text { penyayang. }\end{array}$ & днашик & $\circ, 15$ \\
\hline 5 & $\begin{array}{l}\text { Kinapulu, (orang tua } \\
\text { dari Kambampu) }\end{array}$ & acuh tak acuh. & Analitik & 27 \\
\hline 6 & $\begin{array}{l}\text { Si Hasani (teman } \\
\text { pengiring Jibirilu }\end{array}$ & setia dan patuh & Analitik & 15 \\
\hline
\end{tabular}

\subsubsection{Latar (setting)}

Latar adalah tempat terjadinya peristiwa-peristiwa dalam suatu cerita, latar belakang fisik serta unsur tempat dan waktu dalam suatu cerita. Latar menunjukkan kepada pembaca kapan dan di mana peristiwa itu terjadi serta mempunyai hubungan dengan eksposisi. Ada tiga hal yang perlu dipertimbangkan dalam kaitannya dengan setting, yaitu waktu, tempat, dan atmosfir. Adapun latar yang terdapat dalam cerita Bungaeja, kita dapat memahaminya melalui tabel berikut. 
Tabel 4

Latar dalam cerita Bungaeja

\begin{tabular}{|c|c|c|c|}
\hline No. & Latar & Kalimat atau Paragraf & Keterangan \\
\hline 1 & $\begin{array}{l}\text { Kampung } \\
\text { seberang }\end{array}$ & $\begin{array}{l}\text { 1)Ada seorang putri yang cantik jelita di } \\
\text { kampung seberang,... }\end{array}$ & Tempat \\
\hline & Negeri lain & $\begin{array}{l}\text { 2) Sekali peristiwa, datanglah seorang } \\
\text { pemuda yang gagah perkasa, dari negeri lain. } \\
\ldots\end{array}$ & Tempat \\
\hline 2 & Malam & $\begin{array}{l}\text { 3Sebelum merantau, Jibirilu pernah tidur } \\
\text { tujuh hari tujuh malam.... }\end{array}$ & Waktu/atmosfir \\
\hline 3 & Suasana sedih & $\begin{array}{l}\text { 6... Keberangkatan mereka itu membawa } \\
\text { suasana kesedihan dan keharuan bagi keluarga } \\
\text { yang ditinggalkan, terutama orang tuanya. ... }\end{array}$ & Suasana/atmosfir \\
\hline 4 & $\begin{array}{l}\text { Pantai negeri } \\
\text { lain/seberang }\end{array}$ & $\begin{array}{l}\text { 7)... setelah tiba di pantai negeri yang dituju, } \\
\text { mereka memukul gong tujuh kali sebagai } \\
\text { tanda berlabuh.... } \\
\text { 9) Petugas keamanan kampung segerah } \\
\text { melaksanakan tugas, yaitu turun ke pantai } \\
\text { menemui kaum pendatang itu, sekaligus } \\
\text { menanyakan hal ikhwal mereka sekaligus } \\
\text { maksud kedatangannya di negeri itu. }\end{array}$ & Tempat \\
\hline 5 & Suasana sepi & $\begin{array}{l}\text { 7)...Bunyi gong itu merambat ke seluruh } \\
\text { negeri dan memecahkan suasana sepi di negeri } \\
\text { itu.... }\end{array}$ & Suasana/atmosfir \\
\hline
\end{tabular}

6 Suasana 7)... Dengan bunyi gong itu suasana negeri berkabung itu menjadi gempar, karena waktu itu rakyat sementara berkabung atas kematian Sapati,

Suasana/atmosfir ayah Bungaeja, yang belum lama meninggal.

7 Kediaman istri (12)Selesai mereka diwawancarai petugassapati petugas itu segera kembali ke kediaman istri almarhun/ista Sapati almarhum untuk melaporkan Tempat

\begin{tabular}{|c|c|c|}
\hline & $\begin{array}{l}\text { almarhun/ista } \\
\text { na }\end{array}$ & $\begin{array}{l}\text { Sapati almarhum untuk melaporkan } \\
\text { keterangan mereka. }\end{array}$ \\
\hline 7 & Perahu & $\begin{array}{l}\text { (12)... Utusan itu segera pergi ke perahu } \\
\text { memanggil Jibirilu. .. }\end{array}$ \\
\hline 8 & & (14)Setelah \\
\hline & Kolong rumah & $\begin{array}{l}\text { Suasana bahagia yang mendalam } \\
\text { Pelabuhan di negeri Jibirilu }\end{array}$ \\
\hline
\end{tabular}

\section{Tempat}

Kolong rumah 10 Pelabuhan di negeri Jibirilu

datanglah Jibirilu ke istana; dari jauh terlihatlah oleh dia sang Putri sedang 
bermain-main di kolong rumah...

Tempat Suasana/atmosfir Tempat

(27)Kini, Kambampu

diliputi suasana bahagia

yang mendalam,

meskipun pernikahan

mereka belum

dilangsungkan. ...

(30)... Barisan

penjemput telah berjajar

di pelabuban menanti

kedatangan mereka.

Begitu pula dengan alat-

alat kerajaan telah

disediakan oleh rakyat di

negeri itu. 


\section{PENUTUP}

Memahami keseluruhan hasil dan pembahasan di atas, dapatlah disimpulkan sebagai berikut.

\section{a. Struktur Intrinsik Sastra Lisan La Dhangu Sarina}

Tema cerita La Dhangu Sarina adalah La Dhangu Sarina dengan ukuran postur tubuh lebih dari manusia biasa. Sedangkan amanatnya adalah; pertama, orang tua hendaknya dapat mengarahkan atau membimbing potensi anaknya. Kedua, manusia hanya dapat merencanakan, akan tetapi Tuhan-lah yang menentukan segalanya. Cerita ini menggunakan plot maju, lurus, progresif. Sedangkan tokoh utama adalah La Dhangu Sarina. Tokoh tambahan adalah ayah La Dhangu Sarina, Raja Wolio, utusan Kompeni. Penokohan atau perwatakan yang digunakan adalah penokohan analitik. Sedangkan latar cerita adalah: waktu, tempat, dan atmosfir.

\section{b. Struktur Intrinsik Sastra Lisan Bungaeja}

Tema cerita Bungaeja adalah kisah cinta Jibirilu dengan Bungaeja. Amanatnya adalah pertama; cinta membutuhkan usaha keras, pengorbanan, ketabahan, baik itu bagi laki-laki maupun bagi perempuan. Kedua; janganlah iri pada kebahagiaan orang lain, karena itu akan berakibat buruk bagi diri sendiri. Cerita ini menggunakan alur lurus, alur maju, atau alur progresif. Sedangkan tokoh utama adalah Bungaeja dan Jibirilu. Tokoh tambahan adalah Kambampu, gadis-gadis cantik teman Kambampu, Sapati (Ibu dari Bungaeja), Kinapulu (orang tua Kambampu), Si Hasani. Penokohan atau perwatakan dalam cerita Bungaeja adalah penokohan secara analitik. Sedangkan Latar (setting) yang digunakan dalam cerita ini adalah: waktu, tempat, dan atmosfir. 


\section{DAFTAR PUSTAKA}

Badudu, J.S. 1984. Sari Kesusastraan Indonesia 1. Bandung: Pustaka Prima.

Endraswara, Suwardi. 2003. Metodologi Penelitian Sastra (Epistemologi, Model, Teori, dan Aplikasi). Yogyakarta: Pn. Pustaka Widyatama.

Esten, Mursal. 1990. Sastra Indonesia dan Tradisi SubKultur. Bandung: Pn. Angkasa.

Gaffar, Zainal Abidin, dkk. 1991. Struktur Sastra Lisan Serawi. Jakarta: Pusat

Pembinaan dan Pengembangan Bahasa Depdikbud.

Garis-Garis Besar Haluan Negara 1999-2004. 1999. Jakarta: Sinar Grafika.

Iye, R., \& Susiati, S. (2018). NILAI EDUKATIF DALAM NOVEL SEBAIT CINTA DI BAWAH LANGIT KAIRO KARYA MAHMUD JAUHARI ALI (Educative Values in Sebait Cinta di Bawah Langit Kairo by Mahmud Jauhari Ali). Sirok Bastra, 6(2), 185-191.

La Djamudi, Nadir. 1994. "Kajian Struktur Sastra Lisan (Dongeng) Masyarakat Kaledupa Kabupaten Buton". Skripsi. Tidak diterbitkan. Kendari: Universitas Haluoleo.

2005. "Relevansi Nilai Sastra Lisan Wolio dengan Kondisi Sosial Budaya Masyarakat Kota Bau-Bau (Suatu Kajian Strukturalisme Genetik)". Tesis. Tidak diterbitkan. Program Pascasarjana Universitas Negeri Makassar.

Mattalitti, M. Arief. dkk. 1985. Sastra Lisan Wolio. Jakarta: Pusat Pembinaan dan

Pengembangan Bahasa, Departemen Pendidikan dan Kebudayaan. Nurgiyantoro, Burhan. 2000. Teori Pengkajian Fiksi. Yogyakarta: Gajah Mada

University Press.

Pradopo, Rachmat Djoko. 1997. Prinsip-Prinsip Kritik Sastra. Yogyakarta: Gajah Madah University Press.

Sande, J.S. dkk. 1998. Struktur Sastra Lisan Wolio. Jakarta: Pusat Pembinaan dan Pengembangan Bahasa, Departemen Pendidikan dan Kebudayaan.

Suhartini, Lelly. 2000. "Wacana Narasi Bahasa Wolio". Tesis. Tidak diterbitkan. Makassar: Program Pascasarjana Universitas Hasanuddin.

Susiati, S., Masniati, A., Tuasalamony, K., Hatuwe, R. S. M., Tahir, S. Z. B., Tenriawali, A. Y., \& Marasabessy, R. N. (2020). MEMBANGUN KETAHANAN RELEGIUS ANAK MELALUI ACTIVE PARENTAL INVOLVEMENT. Jurnal Islam Nusantara, 4(1), 111-125.

Susiati, \& Taufik. (2019). Nilai Pembentuk Karakter Masyarakat Wakatobi Melalui Kabhanti Wa Leja. Jurnal Totobuang, 7(1), 117-137.

Susiati, S., Iye, R., \& Suherman, L. O. A. (2019). Hot Potatoes Multimedia Applications in Evaluation of Indonesian Learning In SMP Students in Buru District. ELS Journal on Interdisciplinary Studies in Humanities, 2(4), 556-570.

Susiati, S., Masniati, A., \& Iye, R. (2021). Kearifan Lokal Dalam Perilaku Sosial Remaja Di Desa Waimiting Kabupaten Buru. Sang Pencerah: Jurnal Ilmiah Universitas Mubammadiyah Buton, 7(1), 8-23.

Susiati, S., Tenriawali, A. Y., Nursin, N., Nacikit, J., \& Mukadar, S. (2020). NILAI EDUKASI DALAM NOVEL PARTIKEL KARYA DEWI LESTARI:(The Value of Education in Particle Novels by Dewi Lestari). Uniqbu Journal of Social Sciences, 1(3), 176-183. 
Susiati, S. (2020). Nilai Budaya Suku Bajo Sampela Dalam Film The Mirror Never Lies Karya Kamila Andini.

Susiati, S., Tenriawali, A. Y., Nursin, N., Nacikit, J., \& Mukadar, S. (2020). NILAI EDUKASI DALAM NOVEL PARTIKEL KARYA DEWI LESTARI:(The Value of Education in Particle Novels by Dewi Lestari). Uniqbu Journal of Social Sciences, 1(3), 176-183.

Tuasalamony, K., Hatuwe, R. S. M., Susiati, S., Masniati, A., \& Marasabessy, R. N. (2020). PENGEMBANGAN PENDIDIKAN KARAKTER DI SEKOLAH DASAR NEGERI 5 NAMLEA. Pedagogy, 7(2), 81-91.

Hatuwe, Rahma Satya Masna., Tuasalamony, Kurniati., Susiati, Susiati, Masniati, Andi., dan Yusuf, Salma. (2021). MODERNISASI TERHADAP PERUBAHAN SOSIAL MASYARAKAT DESA NAMLEA KABUPATEN BURU. Nusantara: Jurnal Ilmu Pengetabuan Sosial, 8(1), 84-96

Susiati, S. (2020). The Concept Of Togetherness In The Films" Aisyah Biarkan Kami Bersaudara" By Herwin Novianto.

Susiati, S. (2020). Eksistensi Manusia Dalam Film" Aisyah Biarkan Kami Bersaudara" Karya Herwin Novianto.

Nurhayati, N., \& Said, I. (2019). Emosi Verbal Suku Bajo Sampela. Sosial Budaya, 16(2), 114126.

Susiati, Y. T. Risman Iye. A. Kesantunan Imperatif Babasa Indonesia Suku Bajo Sampela: Balai Pembinaan dan Pengembangan Bahasa. 2018. Kongres Babasa Indonesia (No. 12, pp. 1-6). Report.

Susiati, S. (2020). Makian Bahasa Wakatobi Dialek Kaledupa.

Tang, Muhammad Rapi. 2001. La Dadok Lele Angkurue Sebuah Legenda dalam Sastra Bugis Klasik. Telaah Filologis dan Struktural-Sermiotik. Disertasi tidak diterbitkan. Bandung: Program Pascasarjana Universitas Padjadjaran.

Wellek, Rene. dan Austin Warren. 1993. Teori Kesusastraan (Diindonesiakan oleh Melani

Budianta, Cet. 3). Jakarta: Penerbit PT. Gramedia Pusaka Utama. Zaidan, Abdul Rozak. dkk. 1996. Kamus Istilah Sastra. Jakarta: Balai Pustaka. 


\section{Lampiran 1}

\section{LA DHANGU SARINA}

1) Pada pertengahan abad kesembilan belas hiduplah seorang yang bemama La Dhangu Sarina di sebuah pulau dalam pemerintahan Kerajaan Wolio. Perawakannya sangat mengherankan karena terlalu tinggi besar.

2) Diceritakannya bahwa La Dhangu Sarina waktu lahirnya telah dapat menghabiskan satu tandan pisang kapok sekali makan. Jadi, telah dapat kita pikirkan bagaimana besar orangnya.

3) Tidak berapa lama, besarlah La Dhangu Sarina. Berpikirlah bapaknya, "Anakku ini sebenarnya adalah anak yang luar biasa. Jadi, sebaiknya perlu diajar dan dilatih bertempur agar menjadi pahlawan negeri, hulu balang raja."

4) Mulailah diajar dan dilatih anaknya Si La Dhangu Sarina itu untuk memegang senjata dan dipukul kayu. Karena tahan dan kuat fisiknya, kayu-kayu yang dipukulkan kepalanya patah-patah, dan lama-kelamaan Si La Dhangu Sarina itu tidaklah lagi merasakan semua pukulan yang mengenai tubuhnya. Sesudah itu mulai lagi dihantam kepalanya dengan batu sehingga batu penghantamnya itu pecah-pecah.

5) Terbetiklah beritanya di istana raja. Disuruh panggil Si La Dhangu Sarina agar datang ke istana. Tinggallah La Dhangu Sarina di dalam istana. Telah menjadi pengawal raja bila menyeberangi sungai biar bagaimana dalamnya, La Dhangu Sarina mendukung raja menyeberang lalu tidak basah.

6) Tiada berapa lama tinggal di istana, raja kedatangan tamu asing utusan Kompeni. Waktu utusan itu berada di istana, ia melihat La Dhangu Sarina. Berkatalah tamu ini dengan herannya, "Dapatkah kiranya orang itu saya bawa berlayar untuk saya perlihatkan kepada penduduk dunia ini, kerena perawakan tubuhnya yang luar biasa besarnya, tiada samanya di dunia ini."

7) Raja sangat berat hati atas permintaan tamunya itu, Cuma waktu itu belum dapat dibawa, nanti pada pelayaran berikutnya. Betapa kecewanya tamu itu karena ketika kembali kali berikutnya di Wolio untuk menjemput La Dhangu Sarina, kiranya sudah beberapa malam La Dhangu Sarina meninggal. "

8) Demikian cerita Si La Dhangu Sarina, tidak jadi keliling dunia untuk disaksikan kepada bangsa-bangsa lain. Demikian. 


\section{Lampiran 2}

\section{BUNGAEJA}

1) Ada seorang putri yang cantik jelita di kampung seberang, Bungaeaja namanya. Selain kecantikannya, juga ia memiliki sifat ramah dan budi baik. Karena itu, banyak orang yang simpati kepadanya. Ayahnya ialah Sapati, yaitu salah seorang anggota Pemerintah negeri itu.

2) Sekali peristiwa, datanglah seorang pemuda yang gagah perkasa, dari negeri lain. Pemuda itu bernama Jibirilu. Jibirilu ialah putra Kepala Kampung. Kehadirannya di negeri ini, ia ingin mencari takwil mimpinya pada beberapa bulan yang Ialu.

3) Sebelum merantau, Jibirilu pernah tidur tujuh hari tujuh malam. Dalam tidurnya itu ia mimpi bertemu dengan seorang putri yang amat cantik di negeri seberang, Bungaeaja namanya. Nama serta wajah putri itu tidak pernah dikenal sebelumnya.

4) Setelah bangkit dari tidurnya Jibirilu bermohon kepada kedua orang tuanya agar disiapkan perahu Iayar beserta awaknya. la akan merantau ke negeri orang, nmulamula permohonannya itu ditolak oleh kedua orang tuanya. Akan tetapi, Jibirilu mendesak terus dan merayu dengan nada lemah-lembut; akhirnya permintaannya itu dikabulkan.

5)Menjelang keberangkatannya, selain disiapkan bekal makanan dan minuman, juga disiapkan nasihat dan pantun. Sebab menurut orang tuanya, itulah senjata yang paling ampuh bagi seorang pemuda di perantauan.

6) Tiba waktunya, Jibirilu bersama temannya yang setia berangkat menuju negeri seberang. Keberangkatan mereka itu membawa suasana kesedihan dan keharuan bagi keluarga yang ditinggalkan, terutama orang tuanya. Grang tuanya hanya berdoa semoga putranya itu selamat dalam perjalanan sampai diperantauan; bahkan sampai tiba di negeri asalnya. Keberangkatannya itu diiringi dengan tangis dan air mata kedua orang tuanya itu seakan-akan penuh pesanan dan harapan.

7) Jibirilu berangkat berbulan-bulan iamanya; setelah tiba di pantai negeri yang dituju, mereka memukul gong tujuh kali sebagai tanda berlabuh. Bunyi gong itu merambat ke seluruh negeri dan memecahkan suasana sepi di negeri itu. Dengan bunyi gong itu suasana negeri itu menjadi gempar, karena waktu itu rakyat sementara berkabung atas kematian Sapati, ayah Bungaeja, yang belum Iama meninggal.

8) PeriIaku Jibirilu itu menurut anggapan masyarakat merupakan suatu penghinaan dan tidak tahu budi bahasa. karena itu, ibu Bungaeja memerintahkan kepada rakyat untuk mengusir orang-orang itu. "Tak ada tempat bagi mereka di negeri ini sendainya mereka itu datang di negeri ini dengan raja, kecuali mereka itu datang kemari dengan maksud baik dan suci, tempatnya amat luas di negeri ini”, kata ibu Bungaeja. 
9) Petugas keamanan kampung segera melaksanakan tugas, yaitu turun ke pantai menemui kaum pendatang itu, sekaiigus menanyakan hal ikhwal mereka sekaligus maksud kedatangannya di negeri itu.

10)Setelah petugas itu bertemu dengan kaum pendatang itu, salah seorang di antara mereka bertanya, "Kalian ini dari mana, apa maksud kalian datang ke negeri ini".

11)Jibirilu menjawab, "Kami dari negeri seberang. Kami datang di sini tentu dengan maksud baik dan suci!” Dengan demikian jelaslah bahwa kedatangan mereka datang di negeri ini bukan dengan maksud jahat, melainkan dengan maksud baik dan suci.

12)Selesai mereka diwawancarai petugas-petugas itu segera kembali ke kediaman istri Sapati almarhum untuk meiaporkan keterangan mereka. Setelah mendengar keterangan itu, istri Sapati almarhum mengutus salah seorang untuk mengambil Jibirilu. Utusan itu segera pergi ke perahu memanggil Jibirilu. Panggilan itu diterimanya dengan senang hati, hanya waktunya mohon di tunda beberapa jam.

13) Setelah itu utusan tadi kembali ke istana. Tiba di istana dilaporkan segalanya kepada permaisuri bahwa Jibiriiu bersedia memenuhi panggilannya.

14)Setelah beberapa jam kemudian, datanglah Jibiriiu ke istana; dari jauh terlihatlah oleh dia sang Putri sedang bermain-main di kolong rumah. Permainannya antara lain Kalasemba dan Katende. Hati Jibirilu mulai berbisik, bahwa putri itulah yang pernah di dalam mimpinya pada beberapa bulan yang lalu. Didekatinyalah putri itu dengan budi bahasa yang sopan-santun; tampaknya putri itu menyambut kedatangan pemuda itu dengan ramah-tamah pula. Saat ituiah terjadi kontak batin sebagai kelanjutan dari mimpinya. Masing-masing memperkenalkan namanya dan setelah saling mengenal, bertambah mesralah kontakan batin mereka meskipun sebenarnya putri itu belum dewasa dan baru pertama kali bertemu. Tetapi, situasi bercerita seakan-akan sudah Iama berkenalan. Dengan begitu Jibirilu benambah kuat keyakinannya, karena ia reia berkorban, baik hana maupun jiwa dan batinnya.

15)Bungaeja muiai berani mengajak dan mendekati Jibirilu bahkan dia dengan ikhlas Putri memperkakak Jibiriiu. Karena itu, Jibirilu dengan ikhias pula mendambakan dirinya untuk tinggal bersama mereka untuk beberapa hari. Kehendaknya itu diterima oleh Bungaeja dan bundanya. Mulai saat itulah ia tinggal bersama mereka dan tidak kembali Iagi ke perahunya. Ia sangat bahagia tinggal di istana. Namun, ia masih terkenang selalu dengan nasib temannya yang tinggal di perahu, di antara temannya itu yang paling setia adalah Si Hasani. Si Hasani inilah yang selalu terbayang selama ia di istana. Karena itu, Jibirilu turun ke perahu untuk mengajak Si Hasani menginab di istna bersana dia. Ajakan itu diterimanya dengan senang hati, ia berkemas iaiu mereka naik ke istna. Mereka disambut dengan gembira oleh Bungaeja dan ibunya. Sambutan yang penuh dengan ramah tamah itu menggugah hati mereka untuk tinggal di istana lebih lama.

16)Hari berganti malam, terang berganti gelap, demikian pula dengan hati Si Hasani menjadi silih berganti. Semuanya sangat simpati sama Jibirilu, tetapi lamakelamaan hatinya berubah. Ia mulai iri kepada Jibirilu dan timbul rasa cemburu 
kepada Jibirilu. Namun, Jibirilu tetap menerima kanyataan itu dengan sikap yang sopan-santun dan hati yang jujur.

17)Pada suatu hari, terdengar berita oleh gadis-gadis di negeri itu, yaitu anak Kenepulu dan kawan-kawannya bahwa ada dua orang pemuda dari negeri seberang tinggal di istana Sapati almarhum.

18)Mereka itu berjumlah empat puluh orang, di antara mereka yang paling cantik ialah Kambampu. Mereka bermaksud akan pergi menyaksikan pemuda dari seberang itu. Yang betindak sebagai ketua rombongan ialah Kambampu. Ia putri Kenepulu.

19)Tak lama kemudian, datanglah mereka ke istana. Kedatangan mereka itu disambut oleh Bungaeja dengan segala senang hati walaupun sebenarnya kedatangan mereka itu mengandung tujuan buruk.

20)Wajah-wajah kedua pemuda itu benar-benar menarik dan mempesona para gadis itu. Oleh karena itu, hati mereka semakin bertambah iri terhadap Bungaeja. Rencana mereka semakin dimantapkan pula agar tujuan meraka dapat tercapai.

21)Mula-mula membujuk Bungaeja untuk bersikap acuh tak acuh terhadap Jibirilu. Menurut mereka sikap yang demikian itu merupakan alat uji bagi Jibirilu. Apakah bermental baik atau tidak. Andai kata sikapnya itu tidak diterima baik oleh Jibirilu berarti itu suatu tanda tidak setia kepadamu, bujuk para gadis itu kepada Bungaeja. Bujukan itu dilaksanakan oleh Bungaeja. Akan tetapi sikap Bungaeja itu tetapi diterima oleh Jibirilu dengan hati yang dingin. Menurut Jibirilu perlakuannya itu adalah wajar karena ia belum dewasa. Akhirnya, tipu daya mereka pada waktu itu tidak berhasil. Dengan demikian mereka kembali ke rumahnya masing-masing dengan hati yang kesal dan kecewa. Namun, mereka itu tidak putus asa, tetapi mencari kesengsaraan dan kehinaan.

22)Waktu beredar terus mengantar Bungaeja ke alam kedewasaan fisik maupun jiwa. Pada saat itulah Jibirilu mengundang kedua orang tuanya untuk menyaksikan pernikahan mereka yang akan diadakan nanti.

23)Pada waktu kedua mempelai sementara duduk bersanding, datanglah rombongan Kambampu sebanyak empat puluh orang di tempat itu. Daya tipu mereka tidak Iagi menggunakan akal, tetapi menggunakan tenaga dalam.

24)Sementara itu, tiba-tiba Kambampu bangkit dari tempat duduknya, lalu pergi ke belakang Jibirilu sambil menepuk bahunya. Dengan seketika cinta Jibirilu beralih kepada Kambampu. Acara pernikahan mereka segera dibatalkan karena Jibirilu cinta Iagi kepada Kambampu, bahkan sebaliknya rasa benci dan muak kalau memandang wajah Bungaeja.

25)Rasa cinta kepada Kambampu tak tertahankan Iagi. Semakin membara sehingga ia segera meninggalkan tempat mengikuti Kambampu. Hadirin mulai geger dan kedua orang tuanya menjadi gehsah termasuk bunda Bungaeja dan Bungaeja sendiri.

26)Jibirilu tidak menghiraukan Bungaeja Iagi, ia pergi bersama Kambampu ke rumahnya. Hal ini disebabkan oleh cintanya semakin bergejolak dalam kalbunya. 
Kepergiannya itu tidak dibiarkan oleh orang tuanya, kedua orang tuanya berusaha menyusul Jibiriiu kemana saja ia pergi.

27)Kini, Kambampu diliputi suasana bahagia yang mendalam, meskipun pernikahan mereka belum dilangsungkan. Sementara itu, tiba-tiba datanglah orang tua Jibirilu di rumah Kambampu. Dengan segala kata yang pedis yang dilontarkan oleh orang tua, baik yang ditujukan kepada Jibirilu maupun kepada Kambampu. Pada dasarnya orang tuanya tidak setuju bila ia kawin dengan Kambampu. Menurut pengakuan orang tuanya mereka setuju kalau ia kawin dengan Bungaeja. Kambampu pun bersedia untuk tidak dikawini, tetapi dengan syarat ia tetap bersama dengan Jibirilu ke mana saja iapergi.

28)Setelah ada kata sepakat dari mereka, Jibirilu bersama orang tuanya kembali lagi ke istana Bungaeja untuk melangsungkan pernikahan mereka, Kambampu ikut bersama mereka.

29)Sampai mereka di istana pernikahan antara Jibirilu dengan Bungaeja dilangsungkan kembali. Setelah beberapa hari perkawinan mereka berselang, Jibirilu bersama orang tuanya kembali ke negerinya, Kambampu rela mengikuti mereka walaupun ia dijadikan sebagai pembantu Bungaeja.

30)Setelah beberapa hari mereka berlayar, tibalah mereka di negerinya. Barisan penjemput telah berjajar di pelabuhan menanti kedatangan mereka. Begitu pula dengan alat-alat kerajaan telan disediakan oleh rakyat di negeri itu.

31)Kecantikan Bungeja menyebabkan semua orang pingsan, semua orang tidak mampu memandang wajah Bungaeja. Begitu pula dengan penghuni istana tidak luput dari peristiwa itu.

32)Karena ayah Jibirilu sudah semakin tua, maka kekuasaannya diserahkan kepada putranya, Jibirilu, untuk meneruskannya. Jabatan itu diterimanya dengan ikhlas dan mulai saat itulah Jibirilu memerintah negeri itu. 
